\title{
Jeomorfolojik Problemlerde Jeofizik Teknikler: Diyarbakır Güneyinde Dicle Nehri'nin Menderesli Vadisinden Bir Vaka Çalışması
}

\author{
Using Geophysical Techniques in Geomorphological Problems: A Case Study From Kavs Flat \\ in Dicle Valley (South of Diyarbakur)
}

\author{
Sabri KARADOĞAN ${ }^{1}$ @ , M. Göktuğ DRAHOR ${ }^{2}$ (D), Catherine KUZUCUOĞLU ${ }^{3}$ (D) \\ ${ }^{1}$ Dicle Üniversitesi, Ziya Gökalp Eğitim Fakültesi, Coğrafya Eğitimi Anabilim Dalı, Diyarbakır, Türkiye \\ ${ }^{2}$ Dokuz Eylül Üniversitesi, Mühendislik Fakültesi, Uygulamalı Jeofizik Anabilim Dalı, İzmir, Türkiye \\ ${ }^{3}$ Laboratoire de Géographie Physique (LGP, UMR 8591), CNRS-Paris 1, U-Pec Univ., Meudon- France
}

ORCID: S.K. 0000-0002-0680-5745; M.G.D. 0000-0002-0858-7366; C.K. 0000-0002-0235-0704

\section{öz}

Diyarbakır kenti çevresinde, Dicle vadisinde nehir drenajının gelişmesiyle ilgili olarak bölgesel jeomorfoloji (kapma, genişleme, dirseklenme, daralma vb.) yanında yerel jeomorfoloji açısından da birçok problem ortaya çıkmaktadır (mendereslenme, teraslanma, kayma, dairesel form vs.). Bu dinamiklerin geçmişteki ve günümüzdeki oluşum süreçlerini ve gelişim seyrini anlayabilmek, vadinin son dönemdeki morfolojik evrimini aydınlatmak ve yeniden yapılandırmak için kullandığımız çeşitli yaklaşımlar arasında; karot sondajı, sedimentlerin analizi ve yorumlanması, ${ }^{14} \mathrm{C}$ tarihlendirmeleri, stratigrafik kesitler, korelasyonlar yeniden yapılandırmada morfometrik analizler ve saha incelemeleri sayılabilir. Jeomorfolojik çalışmalarda ve jeomorfolojik problemlerin aydınlatılmasında kullanılan modern yöntem ve tekniklerden biri de jeofizik uygulamalarıdır. Elektrik özdirenç verileri, özellikle jeolojik birimler arasında yeterli litolojik kontrast olduğunda jeolojik yapıların yeraltı dağılımının belirlenmesinde etkilidir. Bu yöntem, sahadaki jeolojik özelliklerin yorumlanmasına önemli katkılar sağlayabilecek ve birimlerin dağıışını düşey yönde yorumlama imkanı verebilecek sonuçlar üretir. Bu tür bir elektriksel direnç projesi, Dicle nehri yatağının gelişmesiyle ortaya çıkan sorunları ve Diyarbakır kentinin doğu ve güney kesimlerinin şekillenmesini anlamayı amaçlayan bir yöntem olarak Diyarbakır civarında uygulanmıştır. Bu çalışmada, bir araştırma programı çerçevesinde, Dicle Nehri'nin sol yakasında ve Diyarbakır eski kent surlarının altındaki Hevsel Bahçeleri'ne simetrik olarak bulunan Kavs Düzlüğü’ndeki jeofizik çalışmalarının sonuçları sunulmaktadır.

Anahtar kelimeler: Jeofizik, Jeomorfoloji, Diyarbakır

\section{ABSTRACT}

Around the city of Diyarbakir, many problems arise with regard to the evolution of the river drainage in the Tigris valley, in terms of regional geomorphology. Among the various approaches we used for understanding and reconstruting these dynamics in the past as well as for the present, we have performed morphometric analysis and field studies aiming at reconstructing the recent morphological evolution of the valley from coring, sediment interpretation, ${ }^{14} \mathrm{C}$ dating, and stratigraphic correlations between sections and cored sequences, etc. One of the modern methods and techniques used in geomorphological studies and elucidation of geomorphological problems is geophysical prospections. Electric resistivity data are efficient in determining the underground distribution of geological structures, especially when there is sufficient lithological contrast between geological units. This method produces very useful results that provide series of vertical sections that can be important contributions to interpretating geological features on the field. Such an electric resistivity project has been applied in the Diyarbakır vicinity as a method aiming at understanding problems raised by the development of the Tigris river channel and meanders east and south of the city of Diyarbakır. Within the frame of this programme, we present here the results of a geophysical survey of the Kavs Plain on the left bank of the Tigris river below the Diyarbakir City wall.

Keywords: Geophysics, Geomorphology, Diyarbakir

Başvuru/Submitted: 05.04 .2020 • Revizyon Talebi/Revision Requested: 13.05.2020 • Son Revizyon/Last Revision Received: 02.06 .2020 - Kabul/Accepted: 08.06.2020 - Online Yayın/Published Online: 23.06.2020 


\section{EXTENDED ABSTRACT}

One of the modern methods and techniques used in geomorphological studies and elucidation of geomorphological problems is geophysical prospections. Among these methods, electrical resistivity is nowadays widely used in geological research. Its data are efficient in determining the underground distribution of geological structures, especially when there is sufficient electrical contrast between geological units. This method produces very useful results that provide series of vertical sections that can be important contributions to interpretating geological features on the field. In recent years, higher-precision and faster resistivity devices have emerged, also using numerical methods during the data evaluation.

Such an electric resistivity project has been applied in the Diyarbakır vicinity as a method aiming at understanding problems raised by the development of the Tigris river channel and meanders east and south of the city of Diyarbakır.

Aims of the operation were:

- To establish the relationships between the Pliocene-Pleistocene alluvial terraces built up by the Tigris old and present courses. In the area studied, the top alluvial soil forming the valley bottom studied, cover either a basement formed by Upper Miocene-Lower Pliocene-aged Şelmo Formation, or Early Pleistocene coarse alluvial deposits, or similar or thinner alluvial Holocene sediments.

- To identify possible tectonic phenomena.

Geophysic prospection has been realized along the left bank limiting the southern part of the Tigris wide meander at the foot of the city wall. Data were evaluated by a two-dimensional inversion electrical resistivity process (1) evidencing contrasts of resistivity of the sediment units below the ground surface, and (2) allowing an electrical mapping of sections through the units and an analysis of the distribution of these units along the lines explored.

ERT and IPT measurements have been performed along five lines. Coordinates as well as topography records and geophysic data were collected in association with GPS at all measurrement points. ERT work was then carried out on the five lines of different lengths, and organized along different directions that were crossing each other.

The main results from the electrical resistivity tomography (ERT) and induced polarization tomography (IPT) measurements, together with field observations are the following:

- Along the vertical profile of the valley left slope, which cuts the Selmo formation and its Plio-Pleistocene coarse alluvial cover, topographic ruptures are associated with vertical erosion of differently resistant lithology of the bedrock formations. However, stratigraphic observation also suggested deformations underlined by some cliff lines. Geophysical data demonstrate that these deformations are associated with a fault zone composed of an array of small normal faults.

- Along the foot of the left scarp of the river valley, the faulted zone separates the Plio-Pleistocene bedrock from other formations accumulated in the valley bottom. The uppermost unit of this fill presents a high-medium resistivity. Its thickness varies approximately between 20 to 40 meters. The geophysic data point to a coarse-grained alluvial and flood material. Below, another unit presents generally low resistivity values pointing to a high clay content that may characterize the lower levels of the Miocene Selmo formation. If our identification of the geological formations concerned is correct, these results suggest:

- The presence of a high discontinuity of an erosive nature between the Mio-Pliocene clayey formation (that outcrops on the other side of the valley below the city walls) forming the bottom of the valley at this area, and the Plio-Pleistocene alluvial formation above.

- The most probable contribution of the fault zone evidenced in the ERT and IPT results in controlling the displacement of the river in this area. 
- The small normal faults are NW-SE oriented in the western part of the valley course, while some other faults also emerge in the eastern part. The occurrence of the fault signal up to the surface suggests that the system may still be active.

In conclusion, the use of electric resistivity measurements has produced important data concerning discontinuities. These discontinuities have been interpreted as (1) faulted ruptures and (2) stratigraphic unconformities. Both these evidences from the Kavs plain are important contributions to our research programme on the reconstruction of the dynamic geomorphological evolution of the Tigris valley during the Quaternary, and especially its dynamics during the Late Quaternary. In particular, it seems evident that, in this area which is located at the foot of the meandering terraces over which the Hevsel Gardens, which are inscribed on the Unesco World Heritage List as part of a cultural landscape also including the Roman city walls, tectonic may contribute to today's dynamics of the river, in particular its erosion activities. 


\section{GÍRIŞ}

Jeomorfolojik çalışmalarda ve jeomorfolojik problemlerin aydınlatılmasında kullanılan modern yöntem ve tekniklerden biri de jeofizik (Elektrik resistivite) uygulamalarıdır.

Elektrik resistivite yöntemi jeolojik araştırmalarda yaygın kullanılan ve jeolojik birimler arasında yeterli bir elektriksel zıtlık olduğunda jeolojik yapıların yeraltı dağılımını belirleme anlamında efektif sonuç veren bir yöntemdir. Yöntem özellikle tomografik anlamda oldukça yararlı sonuçlar üretmekte ve yorumlamaya önemli katkılar sağlamaktadır (Drahor ve diğ., 2004; Toker, 2014; Uyanık ve Çatlıŏlu, 2014; Şahan ve diğ., 2016). Yöntem, kullanılan bir güç kaynağından çıkan akımın iki elektrot yardımıyla yere verilmesi ve yere verilen bu akımın yeraltında oluşturacağ 1 potansiyelin farklı iki elektrot yardımıyla ölçülmesi ve gerekli hesaplamaların yapılması ilkesine göre çalı̧̧maktadır (Loke ve Barker, 1996a,b).

Sığ yapıların araştırılmasında genellikle yatay resistivite taraması olarak adlandırılan profilleme ölçüm tekniği kullanılır. $\mathrm{Bu}$ teknikte; seçilen elektrot diziliminin türüne bağlı olarak her bir derinlik düzeyi için yapılan ölçümlerle yeraltının görünür resistivite yapma kesiti (pseudo-section) elde edilir. Bu tür bir ölçümün tek kanallı bir resistivite aletiyle yapılması oldukça büyük bir zaman alır. Oysa sığ yapıların araştırılmasında hızlı, duyarlı ve kısa sürede ölçüm yapacak cihazlara gereksinim vardır. Tanımlanan özelliklere sahip olarak üretilen çok kanallı (multi-electrode) cihazlar, bu amaçlar doğrultusunda son y1llarda yaygın biçimde kullanılmaktadır (Dahlin, 2001).

Resistivite yönteminde bilgisayar denetimli veri toplama sistemleri son y1llarda oldukça gelişmiştir. $\mathrm{Bu}$ tür sistemler; resistivite cihazı, bilgisayar, elektrotları denetleyen bir anahtar devre, elektrot kabloları, bunların bağlantıları ve elektrotlardan oluşur (Van Overmeeren ve Ritsema, 1988; Griffiths vd., 1990; Griffiths ve Barker, 1993; Dahlin, 2001). Elektrot aralıkları araştırmacının gereksinimine bağlı olarak istenilen aralıklarda düzenlenmektedir.

Yüksek duyarlıklı ve hızlı veri toplayabilen elektrik resistivite cihazlarının ortaya çıkması, verilerin değerlendirilmesi aşamasında sayısal yöntemlerin kullanılmasını kaçınılmaz kılmıştır. Böylece daha sofistike yorum yapma olanağı ortaya çıkmıştır. Bu gelişmede sonlu farklar ve sonlu elemanlar gibi sayısal yöntemlerin önemi büyüktür. Çözüm tekniklerindeki bu yenilik, değişik birçok elektrot dizilimi için, 2 ve 3 boyutlu düz ve ters çözüm modellemesinin etkili bir biçimde yapılmasını sağlamıştır. Böylece yeryüzü üzerinden değişik derinlik düzeyleri için yapılacak ölçümler yoluyla yeraltının iki- ve üç boyutlu olarak tomogramlarının oluşturulması mümkündür. $\mathrm{Bu}$ yöntemler ile değerlendirmenin en önemli avantajı, ortama ait heterojenitenin bir sadeleştirilmeye ihtiyaç duyulmadan çözüme katılabilmesidir. Böylece kompleks yeraltı yapılarının modellenmesi yapılabilmektedir. Elektrik resistivite tomografi yöntemi özellikle iki boyutlu anlamda son yıllarda dünyada yaygın uygulama alanına sahip olmaya başlamıştır. Özellikle mühendislik ve çevresel sorunlar ile birlikte değişik jeolojik sorunların çözülmesi ve arkeolojik amaçlı uygulamaların ağırlığı da her geçen gün artmaktadır (Drahor ve diğ., 2007; Kurtuluş ve diğ., 2008).

Elektrik resistivite yönteminde yeraltının gerçeğe yakın resistivite dağılımının elde edilmesi görüntülendirme anlamında yapılacak ters-çözüm çalışmalarıyla mümkündür. $\mathrm{Bu}$ yönde geliştirilen ters-çözüm algoritmaları (De Groot-Hedlin ve Constable, 1990; Sasaki, 1992; Loke ve Barker, 1996a,b; Günther vd., 2006) yeraltının tomografik görüntülerinin 2- ve 3-boyutta elde edilmesine olanak sağlamıştır. Ters-çözüm değerlendirmeleriyle tomografi görüntülerine benzer sonuçlar elde edilmesi, bu tip uygulamaların elektrik resistivite tomografisi (Electrical Resistivity Tomography-ERT) olarak ta adlandırılmasına yol açmıştır.

Söz konusu elektrik resistivite uygulamaları tarihi Diyarbakır kenti (Sur) güneyinde Dicle nehri vadisinin genişleyen sol bankında (Kavs Düzlüğü) gerçekleştirildi (Şekil 1).

Bu saha, üzerinde tarihi Diyarbakır kentinin kurulduğu bazalt platosu ile Pliyo Kuvaterner düzlükleri arasında, başlangıçta kuzey-güney yönlü akan Dicle nehrinin bir dirsekle doğuya yönelmeden önce ortaya çıkan dairesel formda bir genişleme alanına karşılık gelir. Bu kesimde nehrin sağ bankı ile şehir surları arasında Unesco Dünya Miras Listesinde yer alan "Hevsel Bahçeleri” bulunur. Bu çalışma bir bakıma bu dairesel genişlemenin ortaya çıkmasına neden olan jeolojik-jeomorfolojik veya tektonik dinamiklerin ipuçlarının bulunmasına yöneliktir.

Çalışma alanı ve yakın çevresindeki en eski litolojik birim Üst Miyosen yaşlı Şelmo formasyonudur. Şelmo formasyonu yer yer marn ara tabakaları içeren kırmızımsı kahve-gri renkli, çapraz tabakalı konglomera kumtaşlarından ve kiltaşlarından oluşmaktadır. Formasyon esas olarak alüvyal yelpaze ve örgülü akarsu ortamlarında çökelmiştir. Şelmo formasyonu üzerine belirgin bir aşınım yüzeyi ile Üst Miyosen-Alt Pliyosen yaşlı Yeniköy formasyonu gelmektedir. Formasyon esas olarak 
konglomera, kumtaşı, silttaşı ve kiltaşlarından oluşmaktadır ve bu birimler çoğunlukla göl ortamlarında çökelmiştir. Üst Miyosen-Alt Pliyosen yaşlı bu karasal birimleri Pliyo-Kuvaterner yaşı Karacadağ Bazaltları uyumsuz olarak örtmektedir. Pleyistosen'de bölgede özellikle Dicle vadisinin kuzey ve doğu kesimlerinde, taşkın enerjili akarsu fasiyesinde masif konglomera çökelimleri olmuştur. Yer yer merceksel geometrili kumtaş1çamurtaşı bankları içeren zayıf tutturulmuş bu konglomeralar, Gölpınar formasyonu olarak adlandırılmaktadır (Çağdaş ve diğ., 2009; Şekil 2).

Vadi boyunca akarsu yatağı çevresinde genç alüvyal taraçaların dolgu malzemesi olarak görülen Holosen yaşlı alüvyonlar ise sahadaki en genç çökellerdir.

Bir süredir çeşitli araştırma programları kapsamında jeomorfolojik ve paleocoğrafik çalışmaların (Kuzucuoğlu ve Karadoğan, 2015; Karadoğan ve Kuzucuoğlu, 2017) yapıldığ Diyarbakır kenti civarındaki Dicle vadisi ve çevresinde nehir drenajının gelişmesiyle ilgili olarak bölgesel jeomorfoloji yanında yerel jeomorfoloji açısından birtakım problemler mevcuttur (kapma, genişleme, dirseklenme, daralma, mendereslenme, yatak genişlemesi, menderes yeniği taraçaları, dairesel formlar vs.).
$\mathrm{Bu}$ dinamiklerin geçmişteki ve günümüzdeki oluşum süreçlerini ve gelişim seyrini anlayabilmek, vadinin son dönemdeki morfolojik evrimini aydınlatmak ve yeniden yapılandırmak için kullandığımız çeşitli yaklaşımlar arasında; karot sondaj1 (Șekil 3), sedimentlerin analizi ve yorumlanmas1, ${ }^{14} \mathrm{C}$ tarihlendirmeleri, stratigrafik kesitler, korelasyonlar yeniden yapılandırmada morfometrik analizler ve saha incelemeleri sayılabilir.

Bugün eski kent surlarıyla birlikte kültürel peyzaj unsuru olarak Unesco Dünya Miras Listesi'nde bulunan Hevsel Bahçeleri'nin üzerinde bulunduğu, nehir yatağına eğimli en az yedi basamaktan oluşan menderes yeniği taraçalarının oluşumunun, bu çalışmada ele alınan söz konusu jeofizik çalışmalarıyla kanıtlanmaya çalışılan olası tektonik olaylarla ilgili olduğu düşünülmektedir (Şekil 3).

$\mathrm{Bu}$ çalışmada ise, program çerçevesinde, Dicle Nehri'nin sol yakasında ve Diyarbakır eski kent surlarının altındaki Hevsel Bahçeleri'ne simetrik olarak bulunan Kavs Düzlüğü'ndeki jeofizik çalışmalarına ve sonuçlarına değinilmektedir.

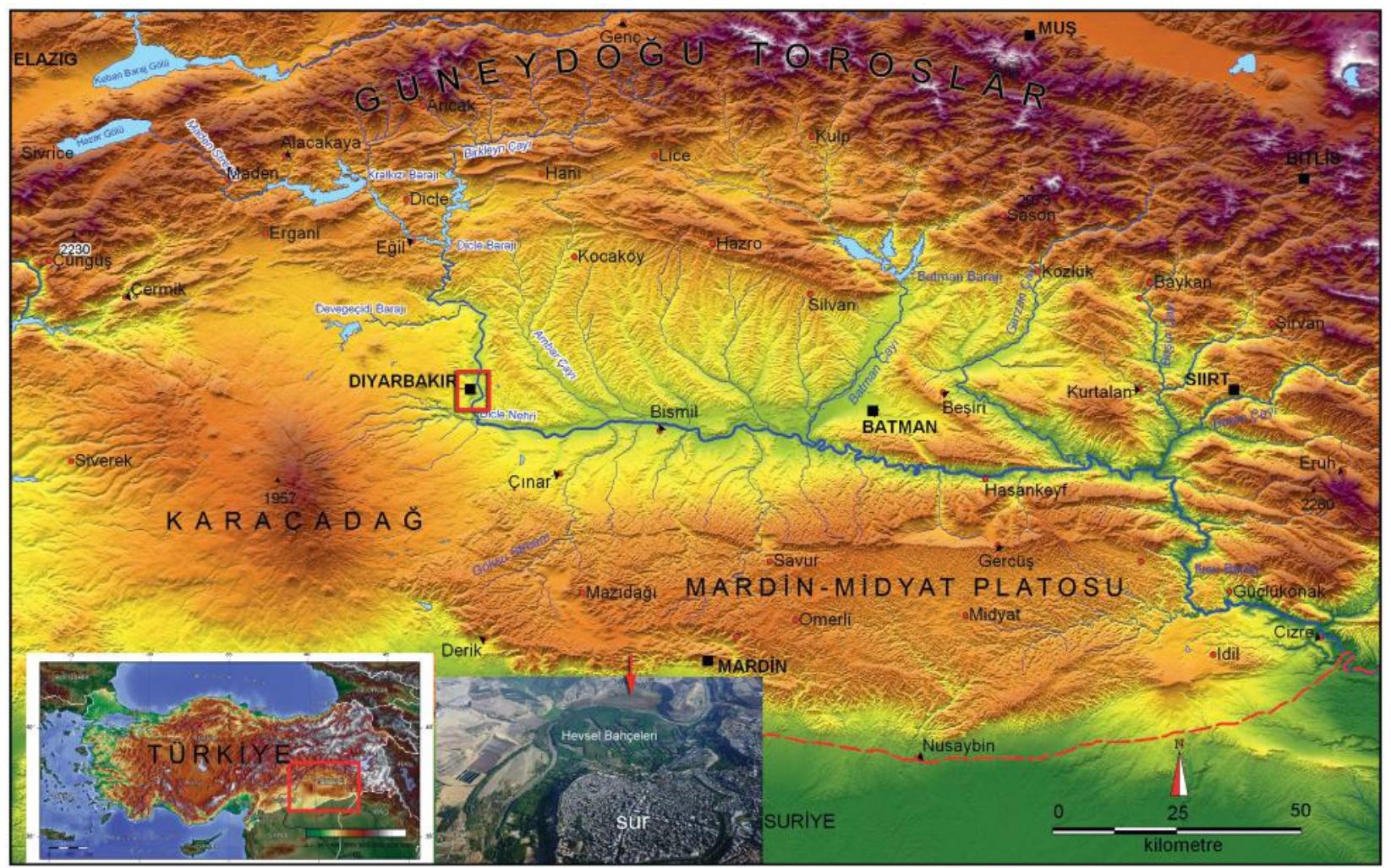

Şekil 1: Çalışma alanının lokasyon haritası.

Figure 1: Location map of the study area. 


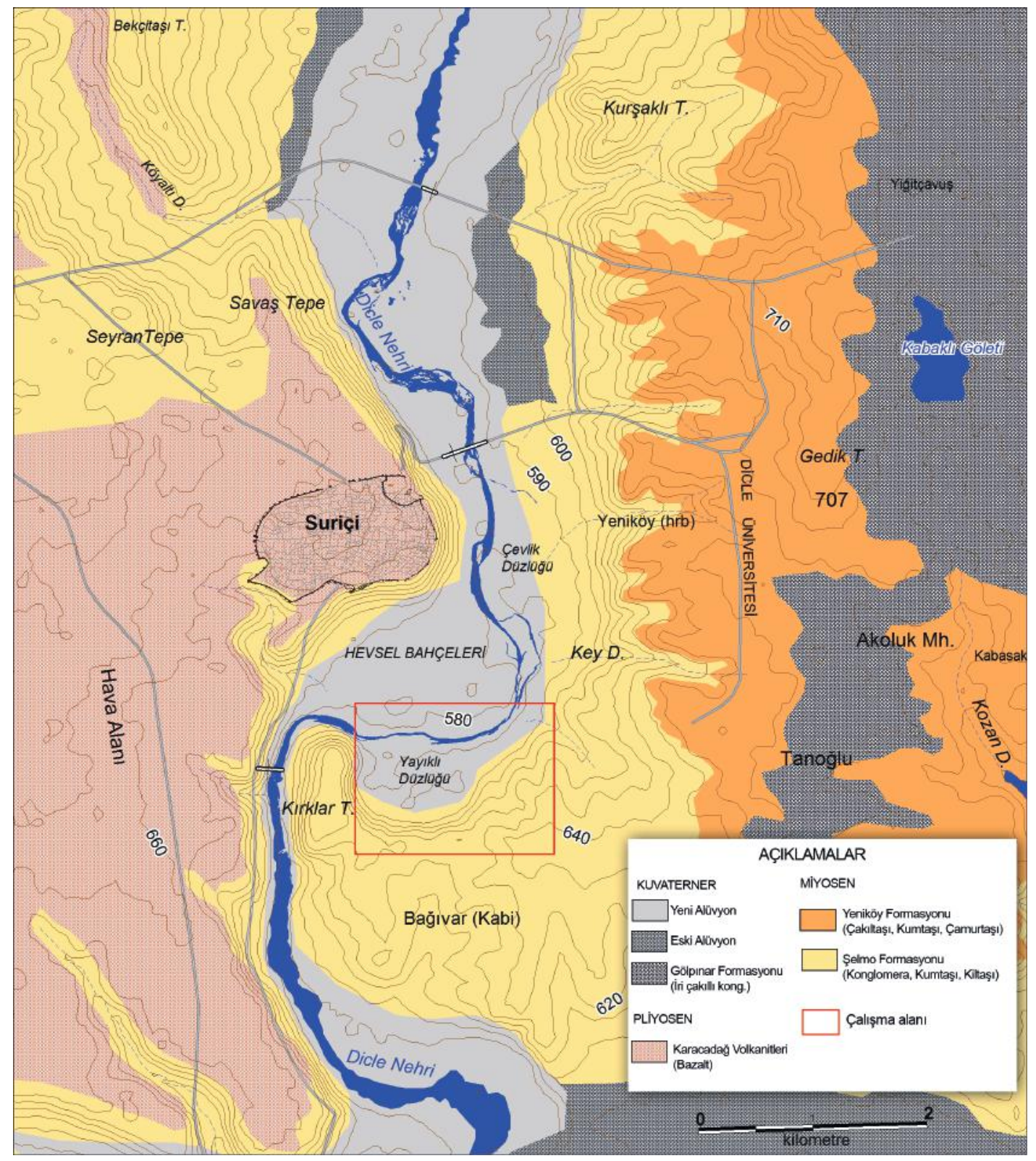

Şekil 2: Çalışma alanının jeoloji haritası (Çağdaş ve diğ., 2009'dan değiştirilerek).

Figure 2: Geological map of the study area (Modified from Çağdaş et al., 2009).

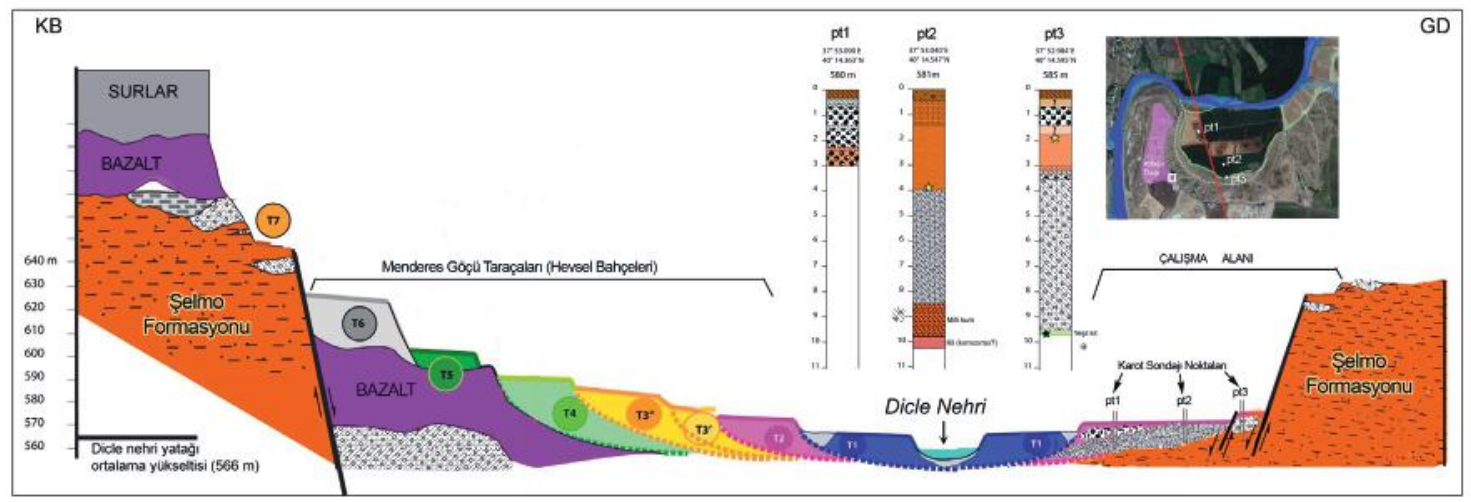

Şekil 3: Çalışma alanı ve çevresinin jeolojik-jeomorfolojik kesiti, karot sondaj noktaları ve stratigrafileri.

Figure 3: Geological and geomorphological cross section, core drilling points and stratigraphies of the study area and its surroundings. 


\section{YÖNTEM- TEKNİK VE MATERYAL}

Eski Diyarbakır kenti (Suriçi) güneyinde Hevsel Bahçeleri'nin simetriğinde nehrin sol bankında yer alan Kavs Düzlüğü'nde yapılan jeomorfolojik çalışmalara veri sağlamak amacıyla elektrik resistivite tomografi (ERT) ve indüklenmiş polarizasyon tomografisi (IPT) çalışması yapılması gereği ortaya çıkmış, bu amaçla 09-11 Eylül 2018 tarihleri arasında belirtilen alanda ERT ve IPT çalışması yürütülmüştür. Çalışmalar sırasında ölçülmesi planlanan hatlarda GPS yardımıyla tüm ölçüm noktalarının koordinat ve topoğrafya ölçümleri de yapılarak, jeofizik veriler toplanmıştır. Çalışma kapsamında menderesin güneyindeki Üst Miyosen-Alt Pliyosen yaşlı Şelmo Formasyonu üzerinde bulunan Pliosen-Pliostosen dönem yüksek topoğrafyası ile Holosen dönem çökelleri arasındaki ilişkiyi kurmak ve olası tektonik olguları belirlemek amacıyla değişik yönlerde ve uzunluklarda Şekil 2'de verilen 5 hat üzerinde ERT çalışması yapılmıştır (Şekil 4).

$\mathrm{Bu}$ çalışmalarda özellikle yüksek topoğrafya ile düşük topoğrafya arasında kalan genel yeraltı karakterini ortaya çıkarmak ve olası fay ve tabakaların geometrik şekillerini ve derinliklerini belirleyerek, bölgedeki jeolojik oluşuma ilişkin bilgilere katkı sağlamaya çalıșılmıștır. ERT ölçümleri ile birlikte indüklenmiş polarizasyon tomografisi (IPT) çalışmaları da yapılarak, kil açısından yoğun olası zonların ortaya çıkarılması da hedeflenmiştir. Hatlardan üç tanesi alanın güneybatı kısmında ve birbirleri ile ilişkili olabilecek biçimde seçilmiştir. Diğer iki hat ise alanda birbirini kesecek biçimde çapraz olarak güneydoğu kesimde alınmıştır. Alanda ölçümler yüksek topoğrafya gösteren

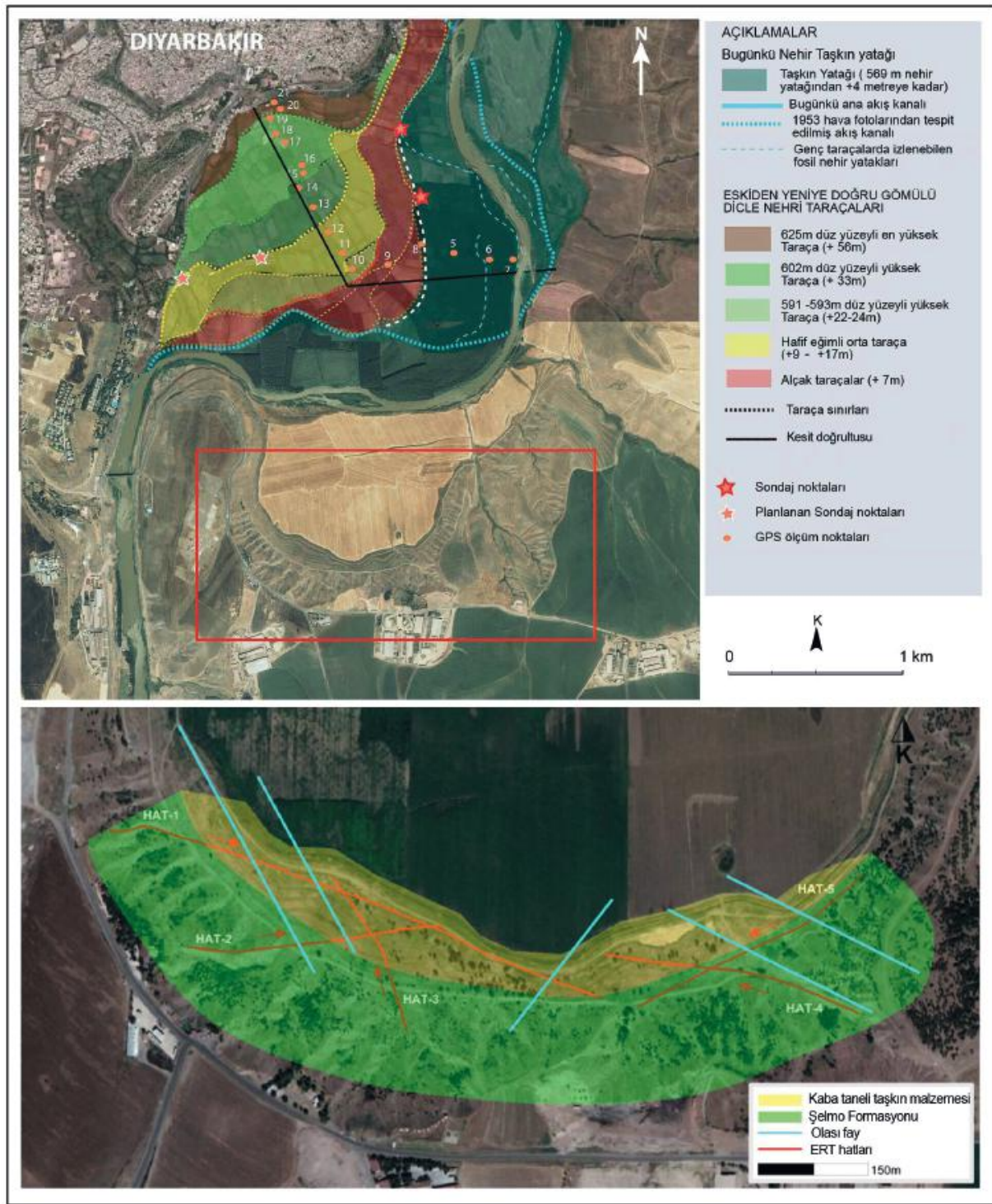

Şekil 4: Diyarbakır kenti güneyinde Hevsel Bahçeleri ve çevresinin genelleştirilmiş jeomorfoloji haritası, ERT yapılan sahanın lokasyonu ve ERT hatları.

Figure 4: Generalized geomorphology map of Hevsel Gardens and its surroundings in the south of Diyarbakır city, location of ERT site and ERT lines. 
kısımlarda alındığından önemli bir eğime sahiptirler. Bu nedenle alanda hat boyunca serimi yapılan ölçüm noktalarına yerleştirilen her elektrot lokasyonunda yüksek duyarlıklı bir GNSS sistem ile GPS ölçüsü alınmıştır. ERT ve IPT ölçümleri sırasında Şelmo Formasyonu'nun killi, kumlu, marnlı ve çakı1lı birimleri ardalanmalı bir dağılım gösterdiğinden ölçüm hatları üzerinde açıkça görülmüşlerdir. Bu birimlerin bulunduğu kısımlar alanda belirlenmiş ve daha sonra ERT ve IPT model kesitleri ile ilişkilendirilmiştir. Hat-4'e çok yakın olan ve ayrıca Hat-5'inde kestiği olası bir süreksizlik belirlenmiştir. Bu süreksizliğin batı kısmında Şelmo Formasyonu'nun üyeleri ve doğu kısmında ise Holosen dönem çökel tabakası görülmüştür. Bu süreksizlik buradaki bir normal faylanma olabileceği gibi, olası bir heyelanın kayma düzlemini gösteren bir heyelan fayı da olabilir.
ERT ve IPT verileri kanallı kablolar serilerek toplanmıştır. Veri toplama sirasinda AGIUSA Sting R1 Resistivite/IP/SP cihazı kullanılmış ve ölçümler toplam 60 kanallı kablo yardımıyla yapılmıştır. Veriler hat uzunluklarına bağlı olarak farklı ölçüm seviyelerinden hem resistivite hem de IP verisi biçiminde elde edilmiştir. Ölçümlere sırasında elektrotlar arası mesafe 12.5 metredir ve hat uzunluğuna bağlı olarak değişik kanal sayılarında veriler toplanmıştır. Böylece 120 ile 40 metre derinliklerine kadar olan ortamlar hakkında bilgi edinilmeye çalışılmıştır. Elde edilen veriler düzgünlük kısıtlı (smoothness constraint) tersçözüm algoritması ile değerlendirilerek, yeraltındaki jeolojik ortamların resistivite değişimlerine bağlı iki boyutlu görüntüleri yorumlanmaya çalışılmıştır. IP verileri de benzer algoritma ile ve resistivite verileri ile ortak ters-çözüm (joint inversion)
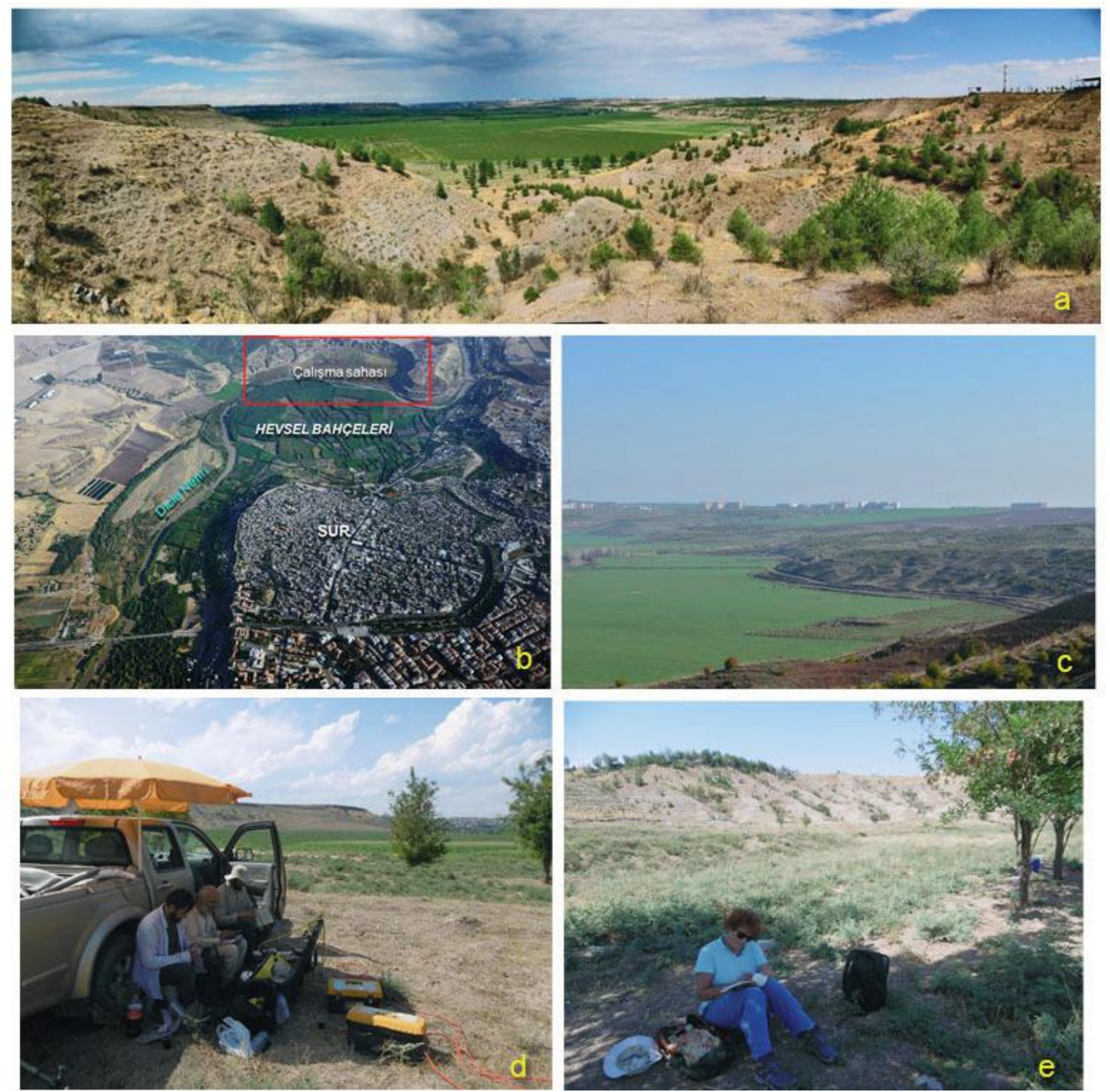

Şekil 5: Sahaya ve çalışmalara ait fotoğraflar. a:Çalışma sahasının panoromik görünümü, b: Çalışma sahasının güneyinden kuzeydoğuya bakış ve

Dicle Üniversitesi Kampüsü, c: Hava fotoğrafından çalışma alanı, d-e : Saha çalışmalarından görüntüler.

Figure 5: Photographs of the field and studies. a: Panoramic view of the study area, $b:$ View to the northeast from the south of the study area and Dicle University campus, c: Study area from aerial photo, d-e: Images from the field work. 
değerlendirmesi yardımıyla elde edilmiştir. ERT verileri 5 yineleme (iteration) sonucunda elde edilirken, IP verilerindeki gürültü oranı nedeniyle 2 ve 3 yineleme ile modeller elde edilmiştir. Elde edilen model eğrilerde $r m s$ hata oranları düşüktür ve veri kalitesinin yüksekliğinden dolayı yeraltındaki dağılımları iyi temsil ettiği düşünülmektedir.

Menderesin güneyinde yapılan bu çalışmaların verileri iki boyutlu ters-çözüm (inversion) işlemiyle değerlendirilerek (De Groot-Hedlin, and Constable, 1990) ölçüm hatlarının iki boyutlu elektriksel resistivite yer altı dağılımları ortaya çıkarılmaya çalışılmıştır. Bu çalışma, özellikle ERT ve IPT model kesitlerine ait bulguların jeofizik yorumunu ve alandaki jeolojikjeomorfolojik özelliklerin daha önce yapılmış olan çalışmalara dayanarak yapılmış özet değerlendirmelerini içermektedir.

\section{BULGULAR}

\section{1. İki Boyutlu Modellerin Yorumlanması}

Hat-1'in ERT ve IPT model kesitlerine ait bulgular: Hat BKBDGD yönlü uzanan ve alandaki en uzun hattır (Şekil 6). Hat uzunluğu 750 metredir ve yeraltının 120 metre derinliğe kadar olan kısmı elektriksel resistivite yardımıyla ortaya çıkarılmıştır.
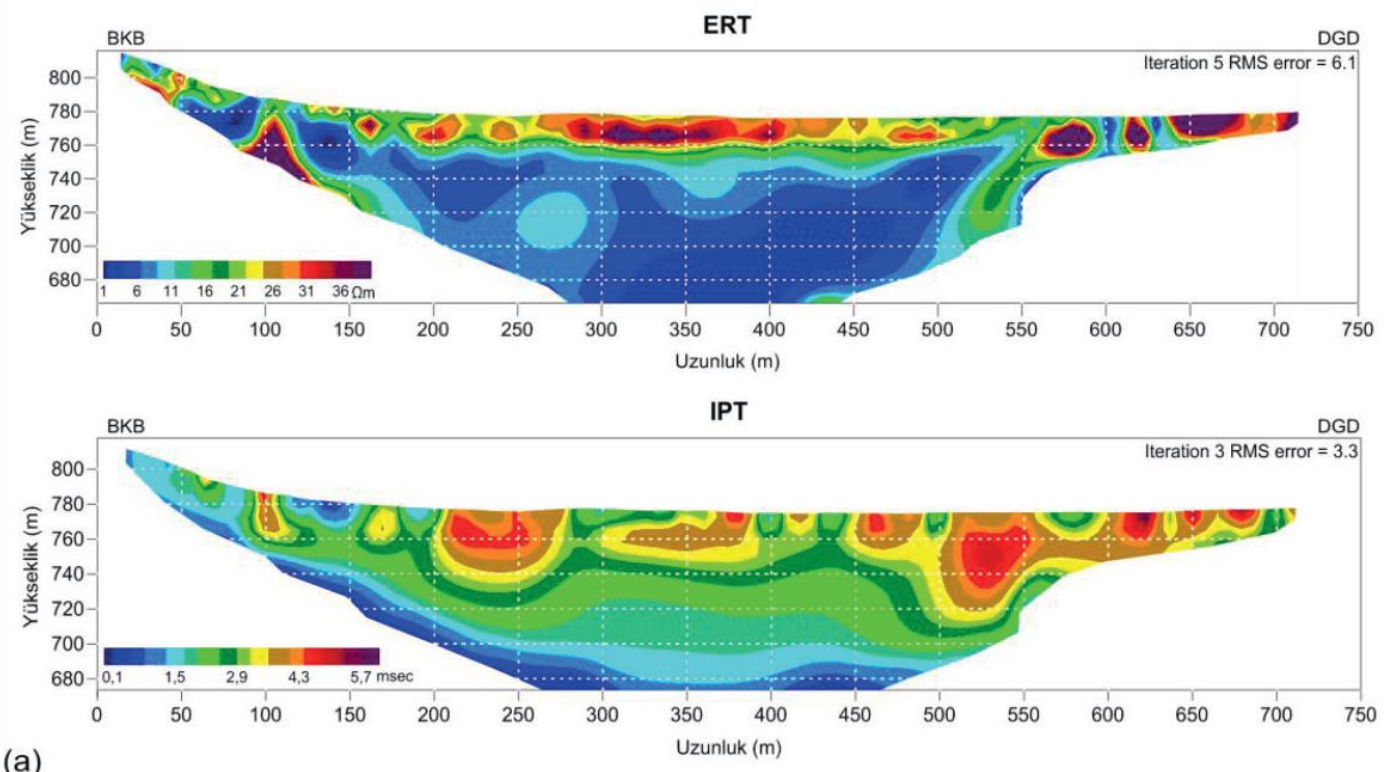

(a)
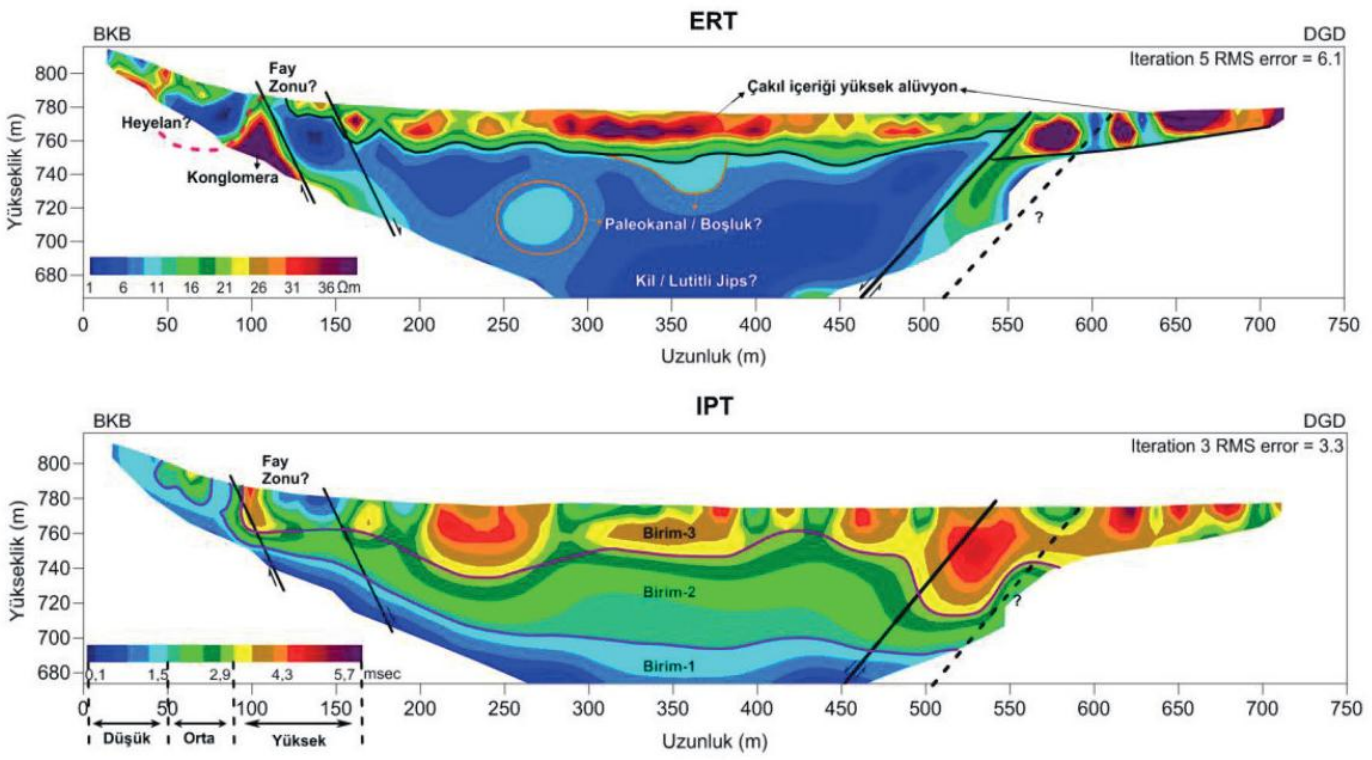

(b)

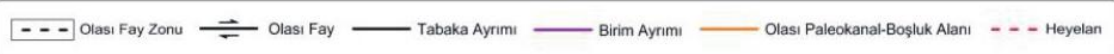

Şekil 6: Hat-1'in ERT ve IPT model kesitleri (a) ve yorumlanmış görüntüler (b).

Figure 6: ERT and IPT model sections (a) and interpreted images (b) of Line-1. 
Olası faylarla ilgili eğimli yüksek resistiviteli zonlar belirgin olarak görülmektedir. Bu zonun altında kil içeriği yüksek bir birim ve üstünde ise yüksek resistiviteli bir tabaka vardır. Model kalın bir çökel dolgusunun varlığını ortaya koymaktadır.

Hat-2'nin ERT ve IPT model kesitlerine ait bulgular: Yaklaşık olarak B-D uzanımlı bir hattır ve Hat-1'i sonuna doğru kesmektedir.
Uzunluğu 375 metredir ve yeraltının 60 metre derinliğe kadar olan kısmındaki yeraltı dağılımının geometrisi elektriksel resistivite yardımıyla görüntülenmiştir (Şekil 7). Hattın ERT model kesitinde 125 metrede bir fayın varlığını gösteren bir değişim bulunmaktadır. Fayın batısındaki yüksek resistiviteli birimler bu alanda elde edilen en yüksek resistivite değerlerine sahiptir ve konglomerakil-kum ardalanmalı seriyi göstermektedir.
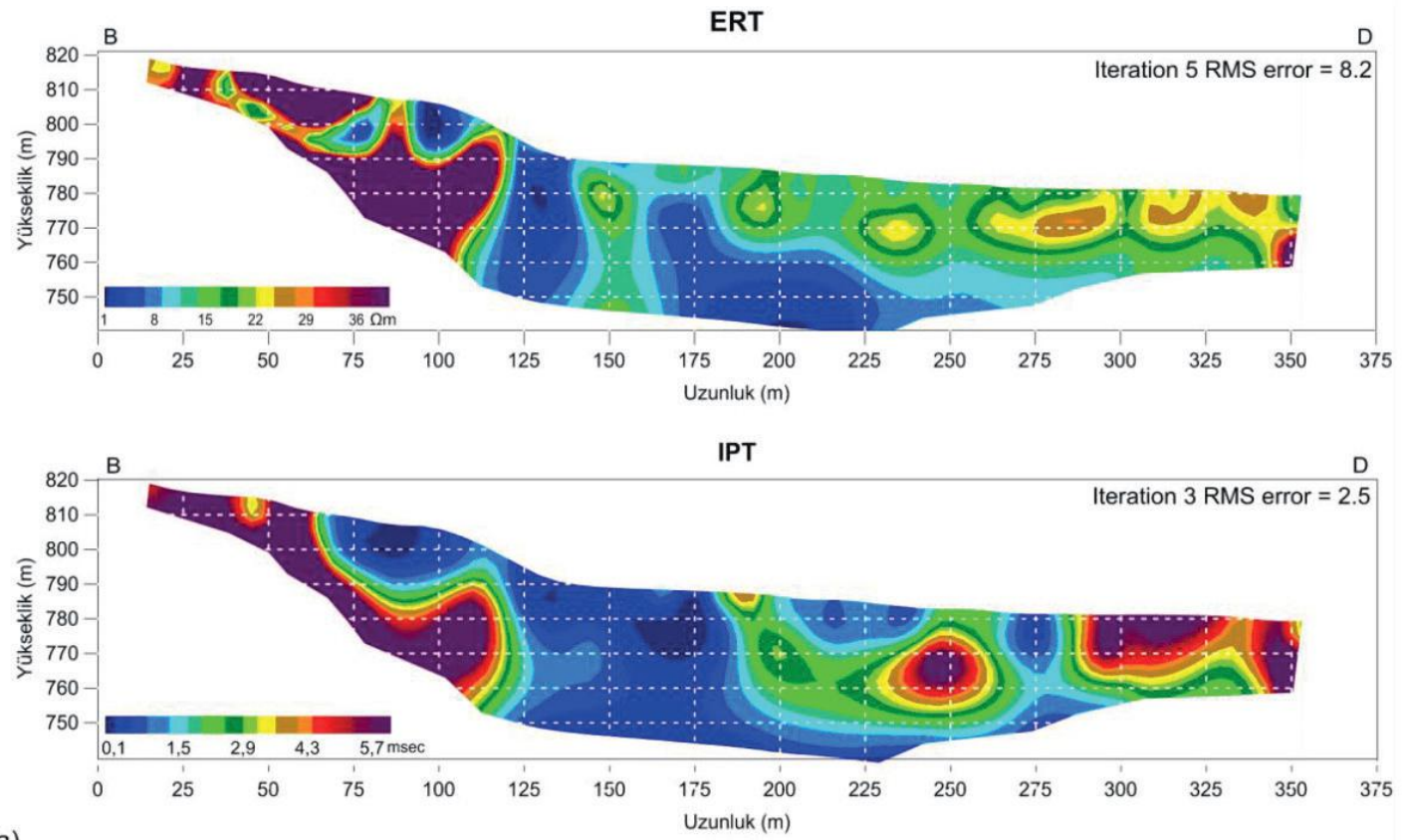

(a)
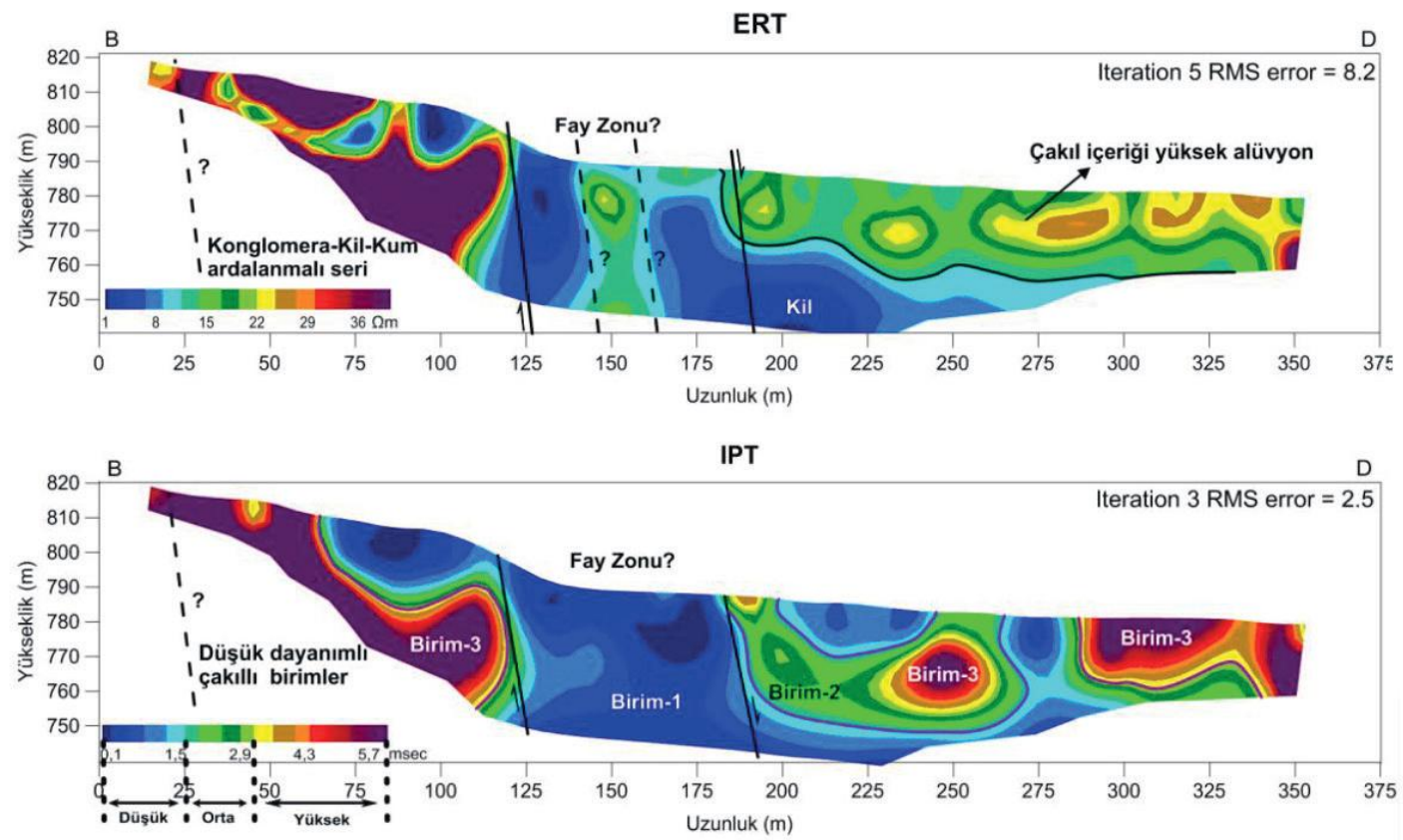

(b)

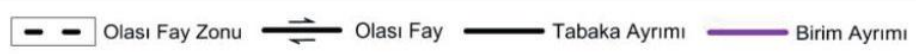

Şekil 7: Hat-2'nin ERT ve IPT model kesitleri (a) ve yorumlanmış görüntüler (b).

Figure 7: Line-2's ERT and IPT model sections (a) and interpreted images (b). 
Hat-3'ün ERT ve IPT model kesitlerine ait bulgular: GGDKKB uzanımlıdır ve 225 metre uzunluğundadır. Hat-1 ve 2'yi kesen bu hat yeraltının 40 metre derinliğe kadar olan yeraltı dağılımını görüntülemektedir (Şekil 8). Bu hattaki amaç diğer hatlardaki faylara dik olası fayların olup olmadığını araştırmaktır. Kaba taneli alüvyon olarak düşünülen bir kama düşük resistiviteli tabaka içine doğru uzanmaktadır. GGD’ya doğru şarjlar devam etmekte ve yaklaşık 90 metrede bir anda son bulmaktadır. Bu durum burada süreksizlik oluşturabilecek bir ortamın olabileceğini düşündürmektedir.
Hat-4'ün ERT ve IPT model kesitlerine ait bulgular: Alanın doğu kısmında alınan ve DKD-BGB yönlü bir hattır. Hat uzunluğu 375 metredir ve yaklaşık 50 metrelik bir derinlik incelenmiştir (Şekil 9). DKD'da alanda görülen pekişmemiş konglomeradan sonra resistivite değerleri düşmekte ve olasılıkla kili bir birime girilmektedir. Killi birimin üstünde ise yine kama biçimli uzanan kaba taneli ve olasılıkla taşkın malzemesi alüvyon bir tabaka bulunmaktadır. Bu tabakanın altındaki killi tabaka ile DKD’daki killi tabaka arasındaki yaklaşık 10 metreden fazla olan seviye değişikliği burada bir fayın olma olasılığını güçlendirmektedir.
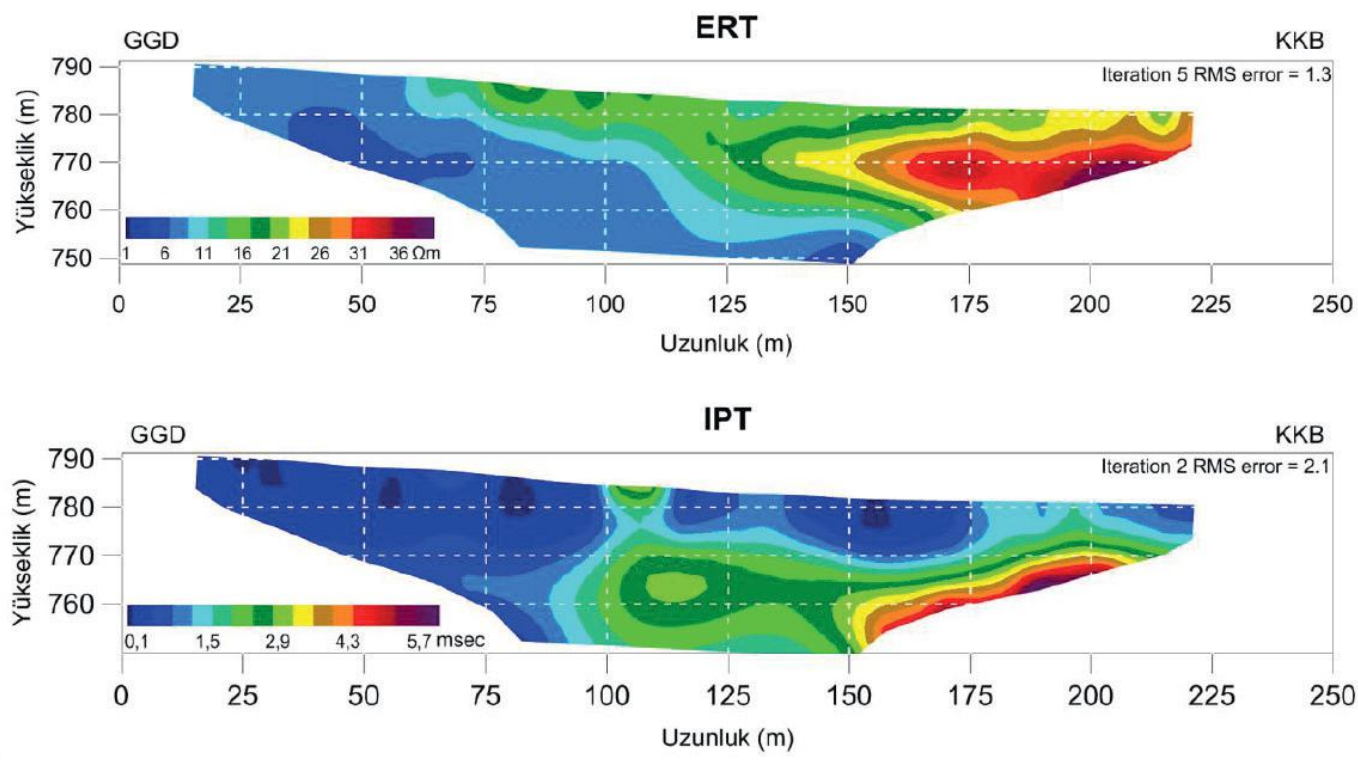

(a)
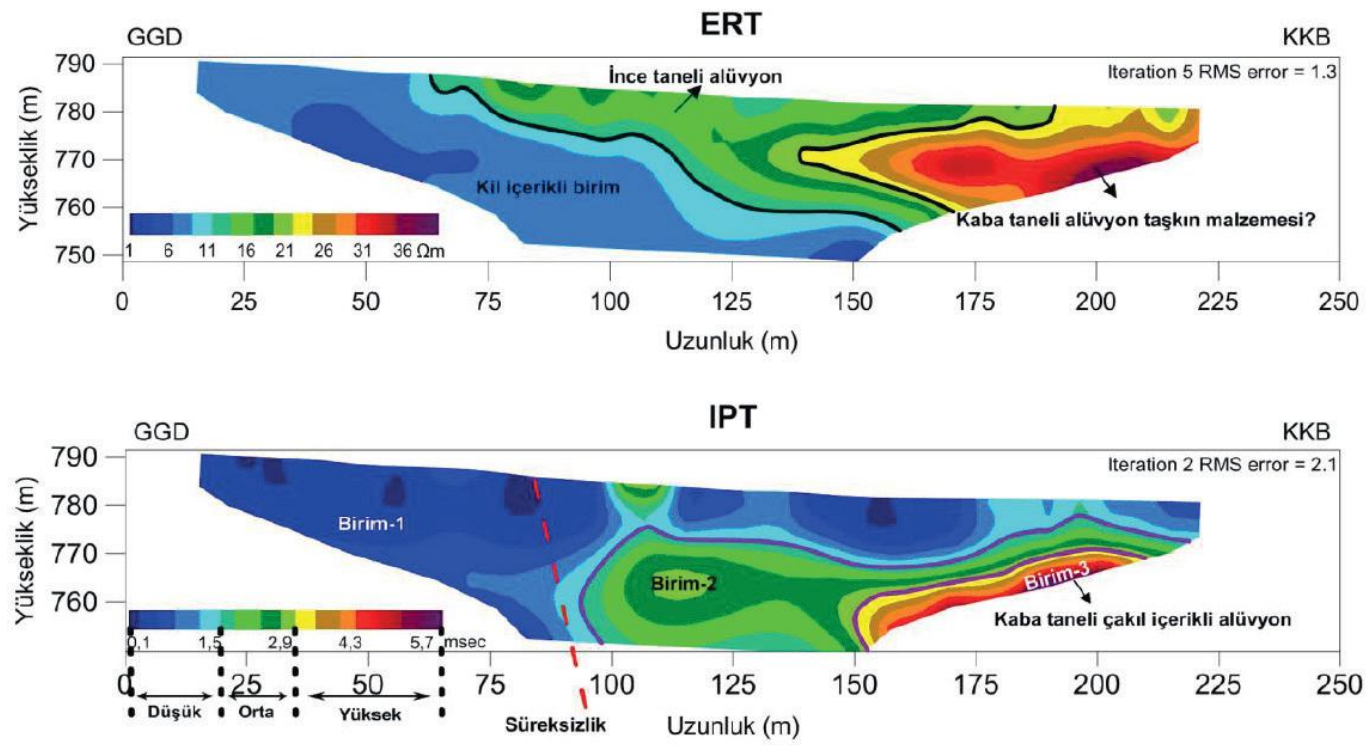

(b)

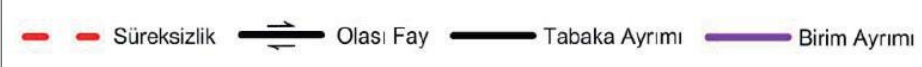

Şekil 8: Hat-3'ün ERT ve IPT model kesitleri (a) ve yorumlanmış görüntüler (b).

Figure 8: ERT and IPT model sections of Line-3 (a) and interpreted images (b). 

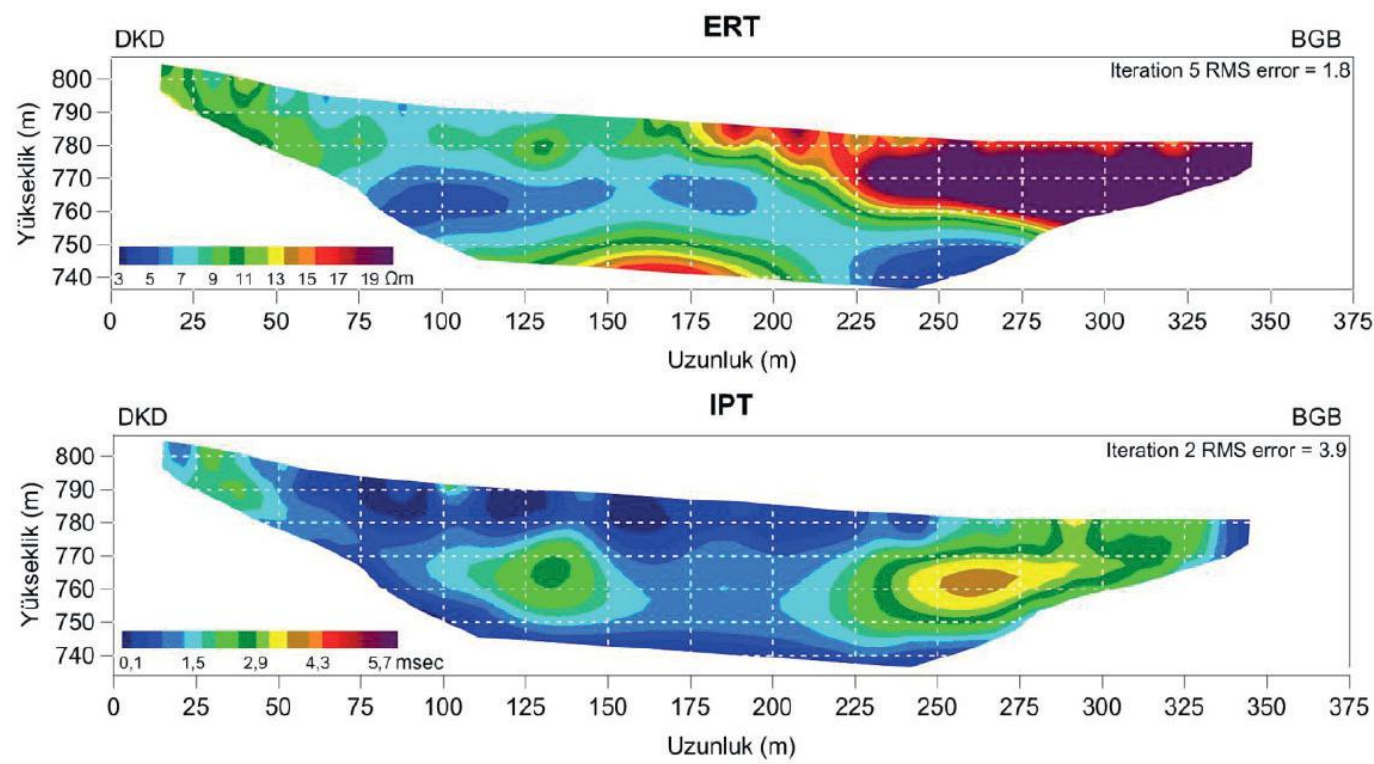

(a)
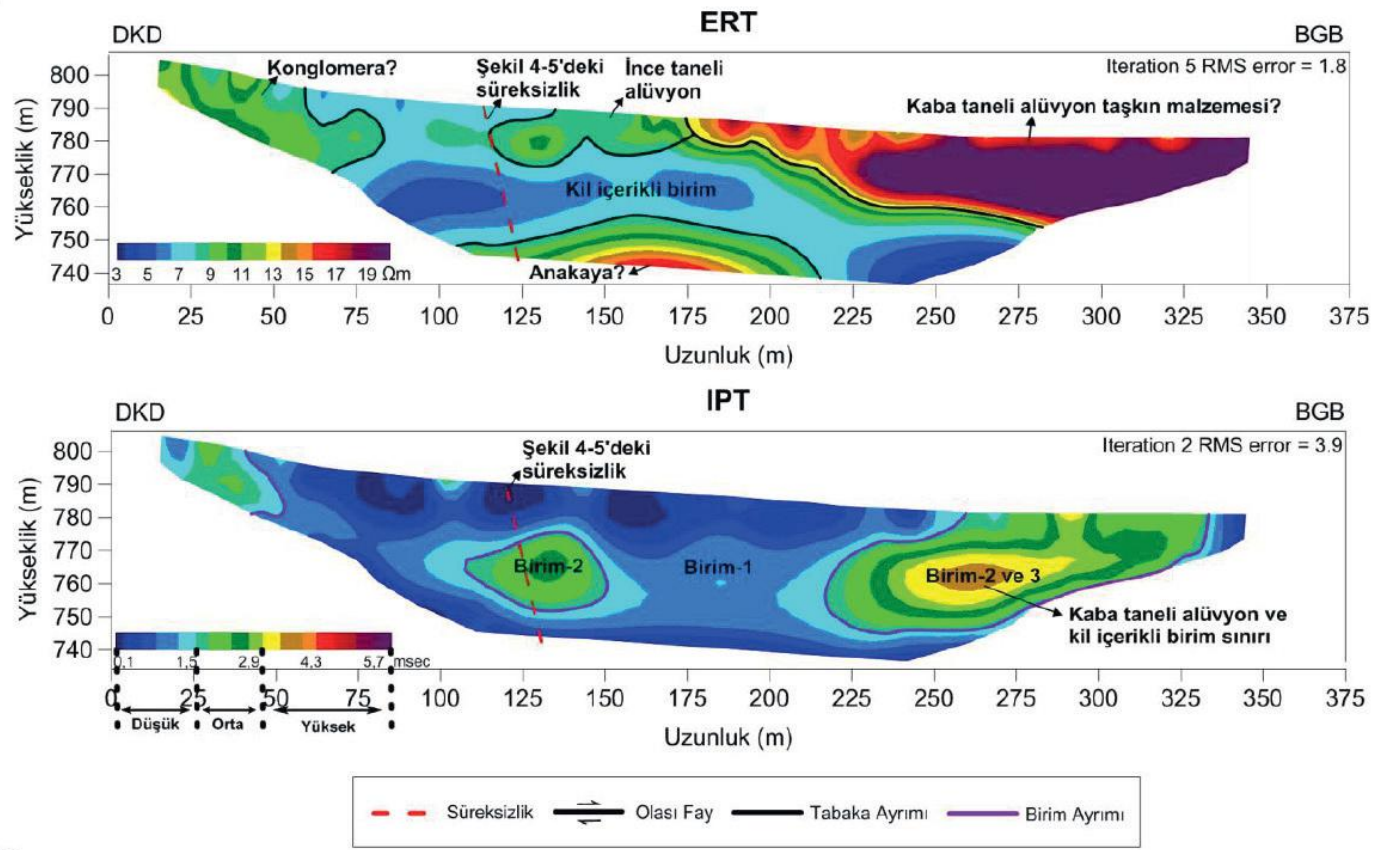

(b)

Şekil 9: Hat-4'ün ERT ve IPT model kesitleri (a) ve yorumlanmış görüntüler (b).

Figure 9: ERT and IPT model sections of Line-4 (a) and interpreted images (b).

Hat-5' in ERT ve IPT model kesitlerine ait bulgular: KD-GB yönlü alınmıştır ve 375 metre uzunluğundadır. Hat olası kenar fayları kesebilmek ve Hat-4 ile kesilme amaçlı alınmıştır (Şekil 10). Model derinliği yaklaşık olarak 50 metreye ulaşmaktadır. 5 ile 15 metre arasında yüzeye yakın yüksek olabilecek resistivitelere sahip bir ortam bulunmaktadır. Kesitlerde olası fay hattı ve ilişkili resistivite ve şarjlanma değişimleri açıkça görülmektedir. Hattın 200 ile 275 metreleri arasındaki kalın alüvyal örtünün buradaki faylanma ile ilişkili olabileceği ön görülmektedir.

\subsection{ERT ve IPT Modellerinin Çit Diyagramları}

Hatlar arasındaki ilişkileri daha iyi ortaya koyabilmek amacıyla ERT modelleri iki ayrı bölge için değişik bakış açılarında çit diyagramları kullanılarak görüntülendirilmiştir. Şekil 11'de Hat-1, 2 ve 3'ün güneybatıdan kuzeydoğuya doğru bakış açısı ile elde edilen çit diyagramı görülmektedir. Değişik açılardan verilen çit diyagramları incelendiğinde bu kısımdaki fayların açık olarak ve ilişkili bir uzanım içinde olduğu görülmektedir. Ayrıca üstteki kaba taneli çökeller de 

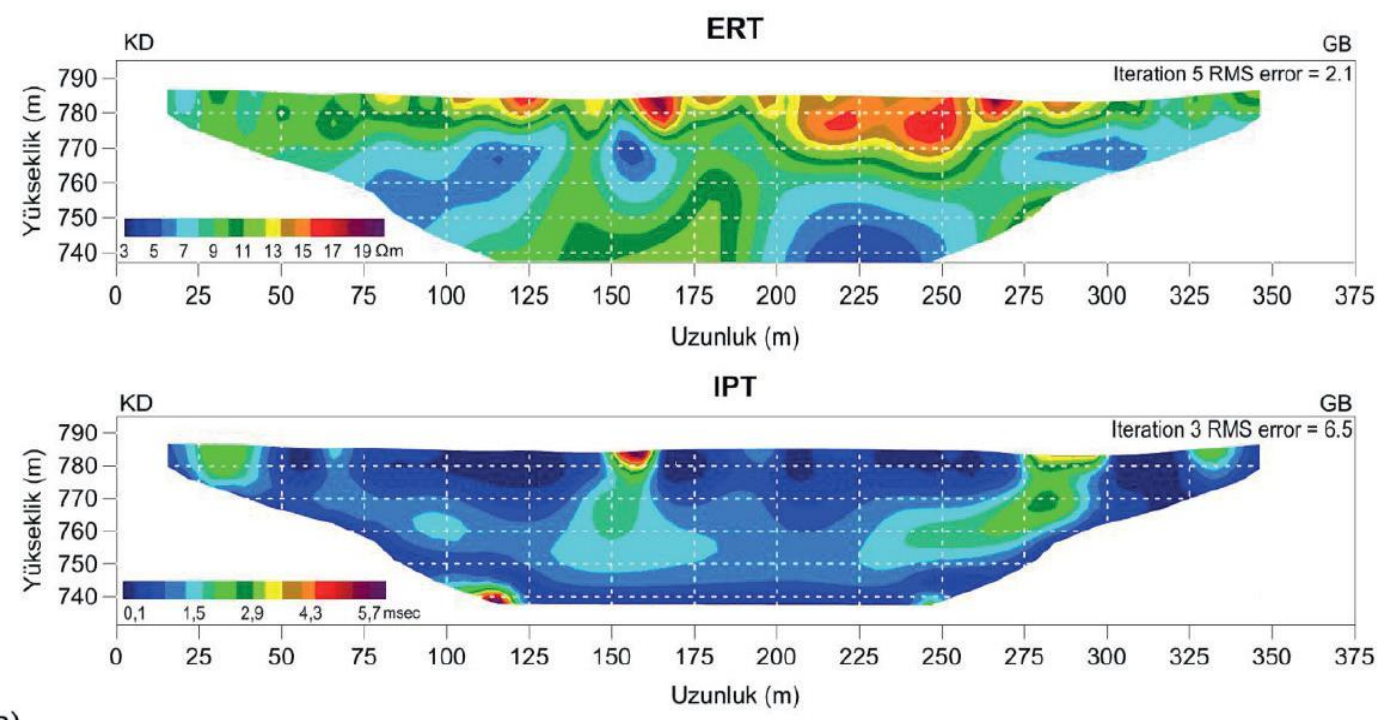

(a)
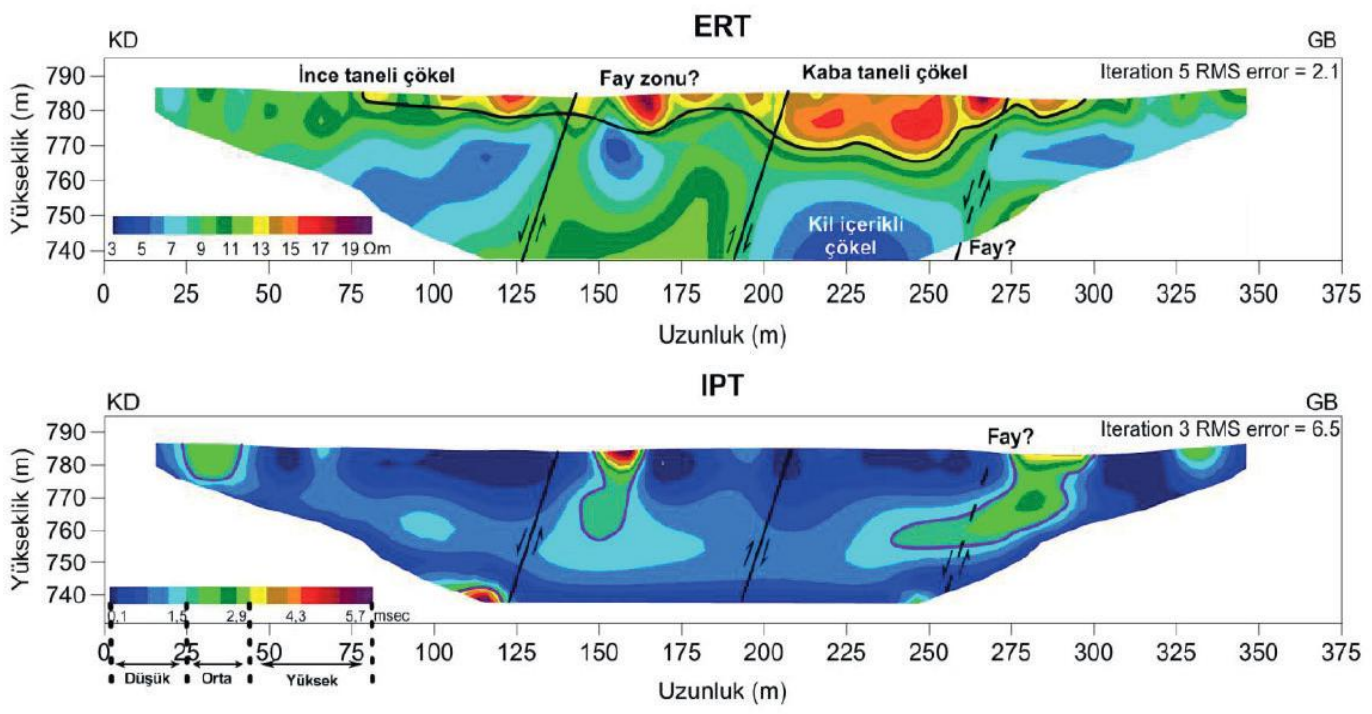

(b)

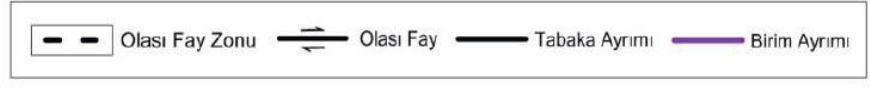

Şekil 10: Hat-5'in ERT ve IPT model kesitleri (a) ve yorumlanmış görüntüler (b).

Figure 10: ERT and IPT model sections (a) and interpreted images (b) of Line-5.

benzer bir ilişki içinde dağılmaktadır. Böylece güneyden kuzeye doğru çökel tabakasının kalınlaştığı ve resistivite değerinin arttığ 1 görülmektedir. Bu durum tipik bir çökme alanı görüntüsü ve onunla ilişkili bir çökel dolgusu karakteri sunmaktadır. Derine doğru resistivitelerde önemli bir düşüş görülmektedir.

Doğudaki bakış açısıyla bakıldığında kesitlerin çok uyumlu olduğu ve kama biçimli çökel topluluğu ile faylanma arasındaki ilişki açık biçimde görülebilmektedir. Faylanmaya bağlı olarak hattın doğusuna doğru resistivitelerde önemli bir azalma bulunmaktadır. Şekil 12'de faylanma ve üstteki çökel tabakaları arasındaki ilişki daha iyi görülebilmektedir.

Aynı biçimde IPT model kesitleri değişik açılardan her iki bölge için çit diyagramları ile görüntülenerek, alandaki IP şarjları arasındaki değişimlerin ilişkisi incelenmeye çalışılmıştır. Batıdaki kısmın IPT çit diyagramı örneklerinden biri Şekil 13'te verilmektedir. IP şarjlanmaları arasında iyi bir ilişki vardır ve genelde kaba taneli çökel içindeki dağılımların birbirini izlediği görülmektedir. Aynı olgu doğudaki alan için de geçerlidir ve şarjlanma değişimleri benzer tabakalar içinde ve faylanmalar ile ilişkili bir dağılım sunmaktadır. 


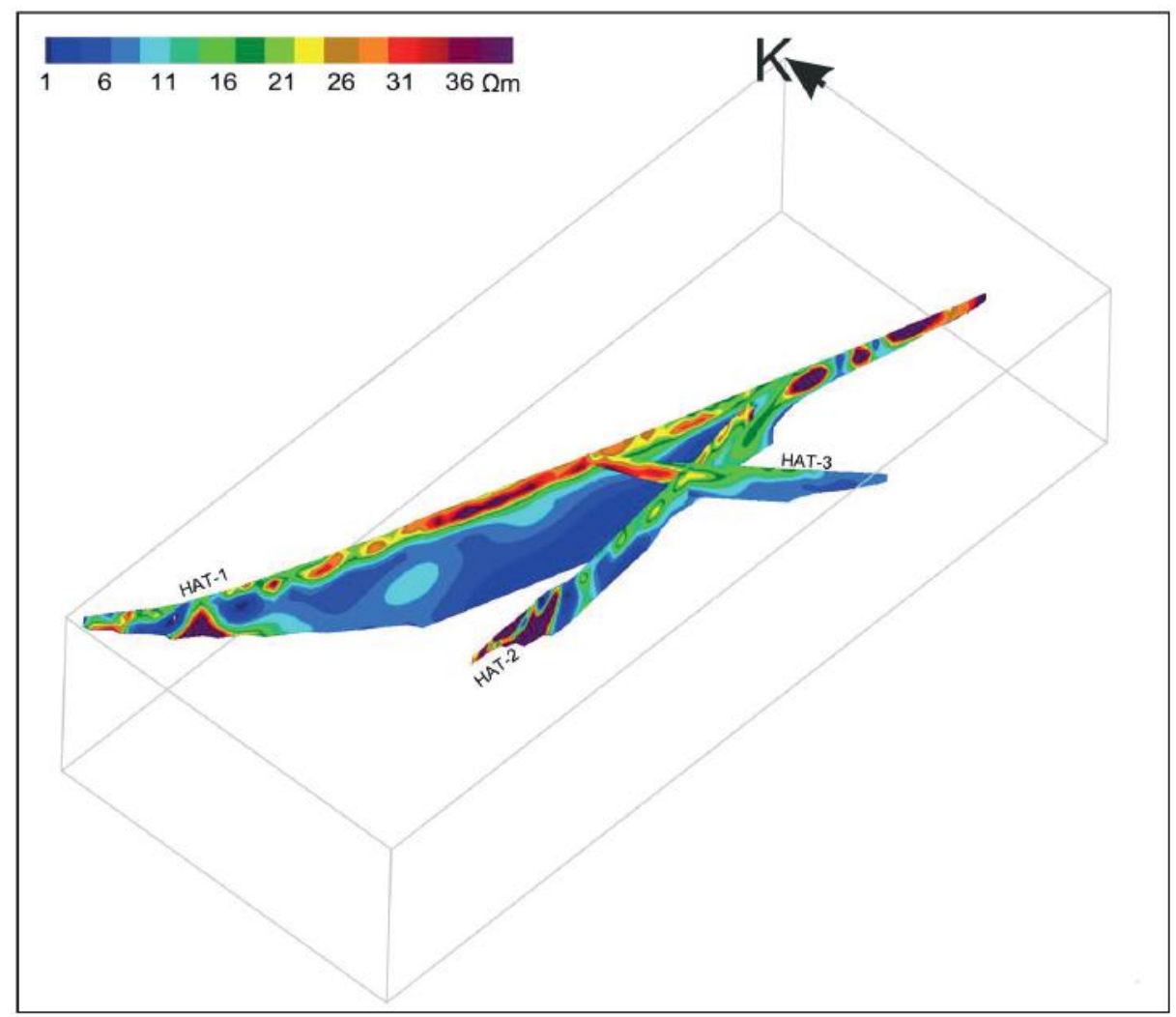

Şekil 11: Hat-1, 2 ve 3'ün güneybatıdan kuzeydoğuya doğru bakış açısı ile elde edilen çit diyagramı görüntüsü. Figure 11: Fence diagram image of Line-1, 2 and 3, obtained from a southwestward to northeast perspective.

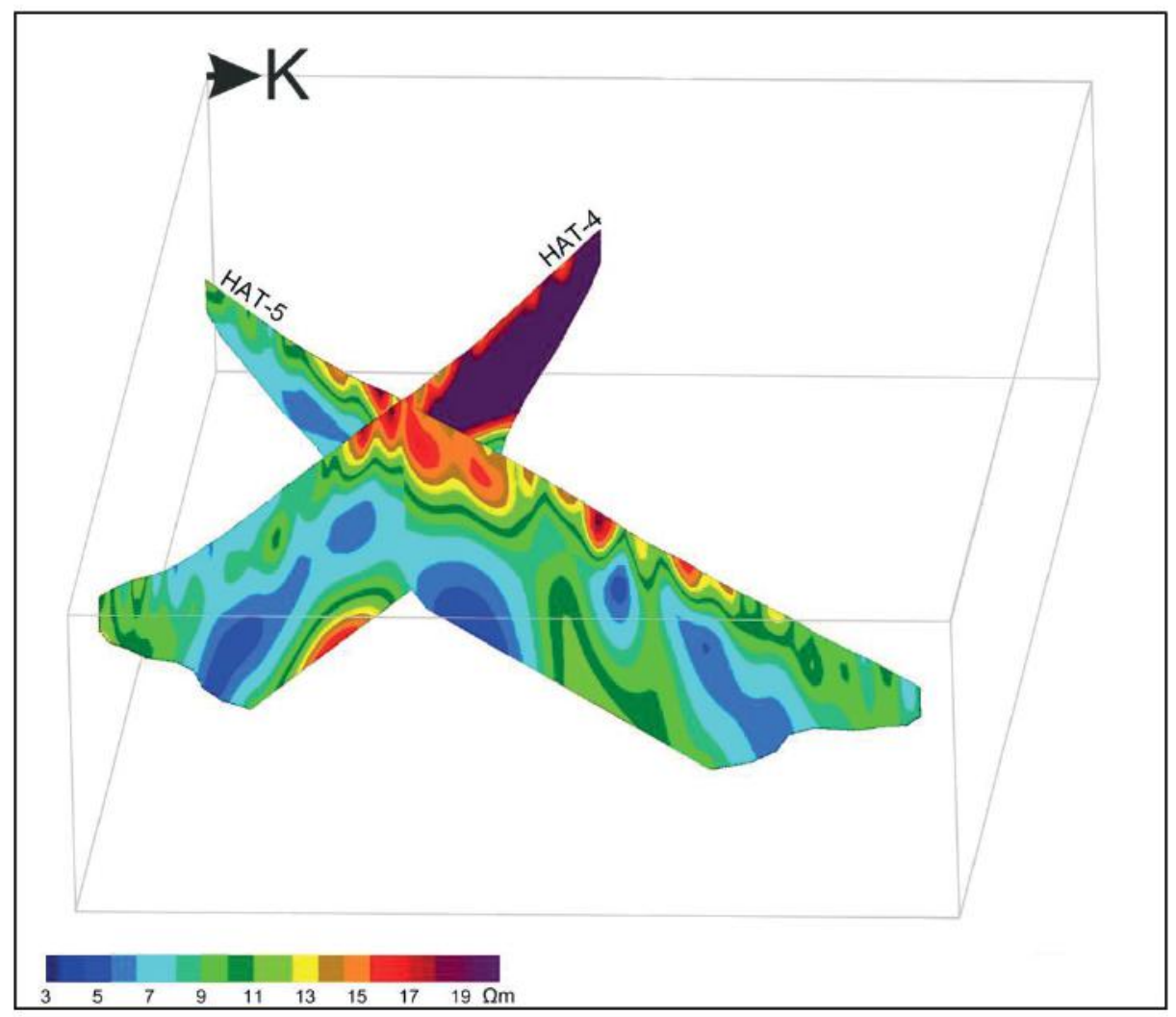

Şekil 12: Hat-4 ve 5'in doğudan batıya doğru bakış açısı ile elde edilen çit diyagramı görüntüsü.

Figure 12: Fence diagram image obtained from the east-west perspective of lines-4 and 5. 


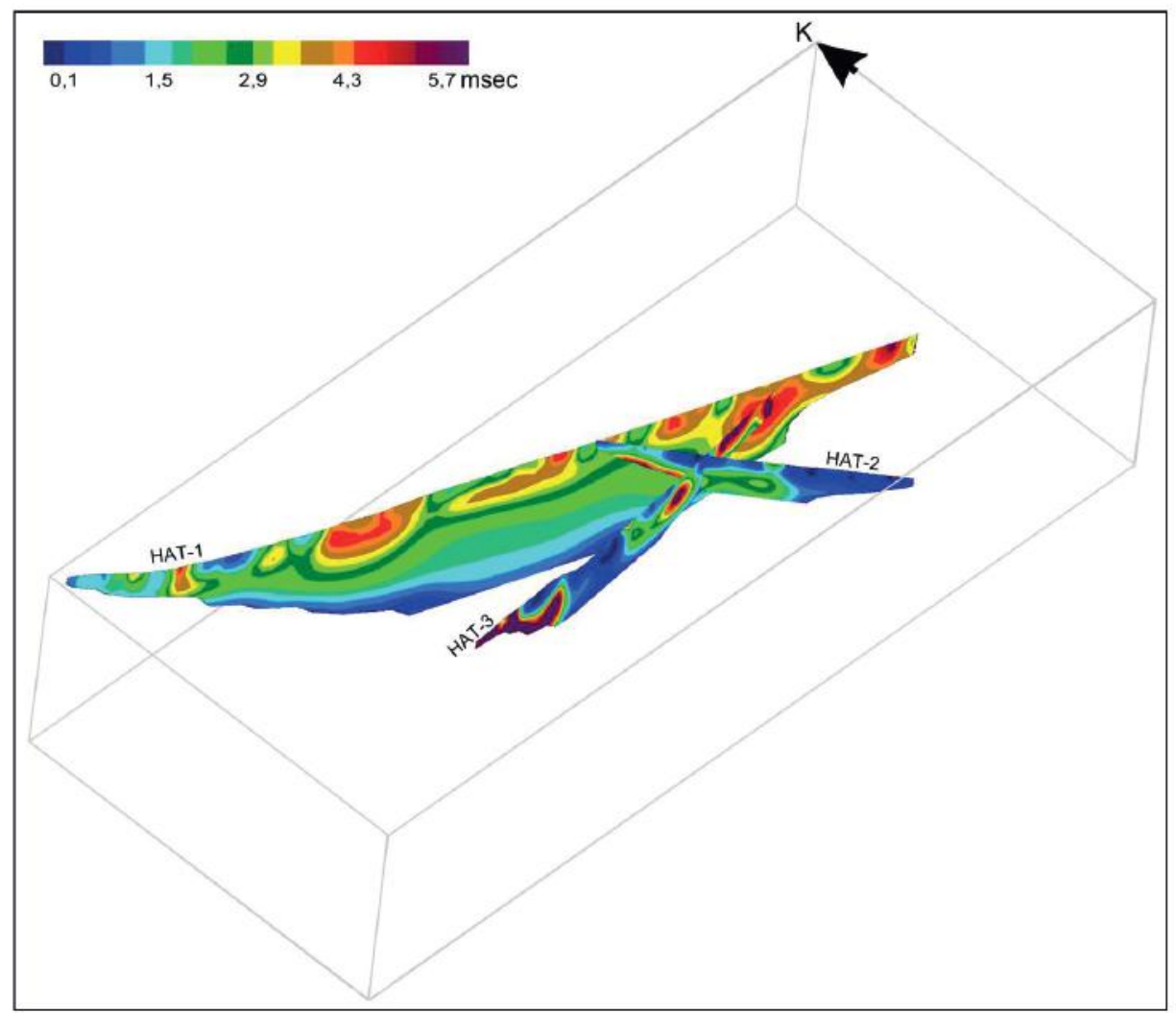

Şekil 13: Hat-1, 2 ve 3'ün güneybatıdan kuzeydoğuya doğru bakış açısı ile elde edilen çit diyagramı görüntüsü.

Figure 13: Fence diagram image of Line-1,2 and 3, obtained from a southwestward to northeast perspective.

\section{SONUÇ}

Diyarbakır kenti güneyindeki Dicle vadisinde Hevsel Bahçeleri'nin simetriği durumundaki Kavs Düzlüğü ve çevresinde, önceki jeomorfolojik çalışmalara destek sağlamak amacıyla uygulanan elektrik resistivite tomografi (ERT) ve indüklenmiş polarizasyon tomografisi (IPT) çalışmaları sonucunda ;

Yüksek topoğrafyadan alçak topoğrafyaya geçilirken, ani eğim olan kısımlarda ve yakınlarında fay segmenti özellikleri taşıyan bulgulara ulaşılmıştır ve normal faylanma olarak yorumlanmıştır. Faylanmaların olduğu kısımlarda düşük resistiviteler yaygın olmakla birlikte ani geçiş olan kısımlarda yüksekten düşüğe doğru bir dağılım söz konusudur. Fay hattının hemen ardından yüzeyde yaklaşık olarak 20 ile 40 metre kalınlığında değişim gösteren yüksek-orta resistiviteli birim kaba taneli alüvyon ve taşkın malzemesi olarak adlandırılmıştır. $\mathrm{Bu}$ birimin altında genel olarak düşük resistiviteli başka bir birim bulunmaktadır. $\mathrm{Bu}$ birimin resistivite değerleri kil içeriğinin yüksek olabileceğini göstermiştir.

Yarım daire biçimli ve kenarlarında önemli diklikler, basamaklar ve fay façetaları olan, içi alüvyonlarla dolu sahada bir çökme olasılığının yüksek olduğu görüşüne ulaşılmıştır. ERT ve IPT sonuçlarında bulunan faylar ile kaba taneli taşkın malzemesi ve Şelmo Formasyonu birimleri bu olguyu doğrulamaktadır. Bu şekildeki fayların batı kısımda olanları KBGD yönlüdür ve normal faylardır. Doğu kısımda da yine benzer yönde bir fay segmenti ortaya çıkmaktadır.

Sistemin halen aktif olduğu düşünülebilir. Elde edilen veriler doğrultu atımlı bir faylanmadan ziyade çökmeye bağlı bir normal faylanma mekanizmasının gelişmiş olabileceğini ve çökellerin de buradaki faylarla birlikte gelişmiş olabileceğini işaret etmektedir.

Yapılan çalışmalar sonucunda ortaya çıkan bulgular, özellikle litolojik birimlerdeki süreksizlikler, kesintiler, düşmeler ve olası kırık hatların geometrisi, doğrultu atımlı tektonik ana hatların yanında Kavs Düzlüğü’nün düşey atımlı çökmelerle de şekillendiği olasılığını güçlendirmektedir. Bugün eski kent surlarıyla birlikte kültürel peyzaj unsuru olarak UNESCO Dünya Miras Listesi'nde bulunan Hevsel Bahçeleri'nin üzerinde bulunduğu, nehir yatağına eğimli en az yedi basamaktan oluşan menderes yeniği taraçalarının oluşumu Kavs Düzlüğü’ndeki söz konusu olaylarla ilgili olmalıdır. 
Teșekkür: Yazarlar Katkılarından dolayı GEOIM LTD ve elemanlarına, özellikle Caner ÖZTÜRK'e, ayrıca saha çalışmalarını ve araştırma giderlerini finanse ettiği için INEE / CNRS ArchéoMed Programına (LGP, Fransa) teşekkür eder.

Hakem Değerlendirmesi: Dış bağımsız.

Çıkar Çatışması: Yazarlar çıkar çatışması bildirmemiştir.

Finansal Destek: INEE / CNRS ArchéoMed Programı (LGP, Fransa).

Acknowledgement: The authors thanks to GEOIM LTD and its employees, especially Caner ÖZTÜRK for their contribution. also thank the INEE/CNRS ArchéoMed Program (LGP, France) for having financed the field operations and data treatments.

Peer-review: Externally peer-reviewed.

Conflict of Interest: The authors have no conflict of interest to declare.

Grand Support: INEE/CNRS ArchéoMed Program (LGP, France).

\section{KAYNAKÇA/REFERENCES}

Çağdaş F. Eminoğlu M. ve Yalçınkaya H. (2009). Diyarbakır'ın imara esas jeolojik durumu, TMMOB Diyarbakır Kent Sempozyumu, 24-26 Nisan 2009, Diyarbakır.

Dahlin, T. (2001). The development of dc resistivity imaging techniques. Computer and Geosciences, 27, 1019-1029.

De Groot-Hedlin, C. \& Constable, S. (1990). Occam's inversion to generate smooth, two dimensional models from magnetotelluric data. Geophysics 55, 1613-1624.

Drahor M. G., Göktürkler G., Berge, M. A., Kurtulmuş T. Ö., Tuna N. (2007). 3D Resistivity imaging from an Archaeological site in South-Western Anatolia, Turkey: A case study, Near Surface Geophysics, Volume 5, Issue 3, Dec 2007, p. 195-201.

Drahor, M. G., Göktürkler, G., Berge, M. A., \& Kurtulmuş, T. Ö. (2004). Dört Farklı Elektrot Dizilimine Göre Bazı Üç-Boyutlu Sı̆̆ Yer Altı Yapılarının Görünür Özdirenç Modellemesi. Yerbilimleri Dergisi, 25(30), 115-128.

Griffiths, D. H. \& Barker R. D. (1993). Two-dimensional resistivity imaging and modelling in areas of complex geology. Journal of Applied Geophysics, 29, 211-226.

Griffiths, D. H., Turnbul, J. \& Olayinka, A. I. (1990). Two-dimensional resistivity mapping with a computer-controlled array. First Break, $8(4), 121-129$.

Günther T., Rücker C. \& Spitzer K. (2006). Three-dimensional modelling and inversion of dc resistivity data incorporating topography. Geophysical Journal International. 166, 506-517.
Karadoğan, S. ve Kuzucuoğlu, C. (2016). Diyarbakır Hevsel Bahçeleri ve Dicle Nehri: Çevresel Değişimlerin Jeomorfolojik Kayıtları (The Hevsel Gardens And The River Tigris in Diyarbakır: Geomorphological Archives of Landscapes Changes), Türkiye Jeoloji Bülteni, Cilt 60, Sayı 1, Ocak 2017, 63-76.

Karadoğan, S. ve Kuzucuoğlu, C. (2018). Diyarbakır Kenti Civarinda Dicle Nehri Taraçalarının Yaş Bulgularına Ait İlk Değerlendirmeler, Dicle Üniversitesi Sosyal Bilimler Enstitüsü Dergisi (DÜSBED) Nisan 2018 YIL-10 Say1 20, s.199-205, ISSN: 1308-6219.

Kurtuluş, C., Bozkurt, A., \& Demirci, C. H. (2008). Tuzla (İstanbul) İlçesi'nde jeolojik, Jeofizik ve Jeoteknik Yöntemler ile Zemin Özelliklerinin Belirlenmesi. Uygulamalı Yerbilimleri Dergisi, 7(2), 10-30.

Kuzucuoğlu, C. \& Karadoğan, S. (2015). The Hevsel Gardens: archives of human activities and of the past and present evolution of the River Tigris at Diyarbakir. In N. Soyukaya (Ed.), Diyarbakır Fortress and Hevsel Gardens Cultural Landscape. Diyarbakır Metropolitan Municipality, Site Management Publications No: 4.

Kuzucuoğlu, C. ve Karadoğan, S. (2017). Chronological and dynamical insights into the Tigris terraces at Diyarbakir. Workshop International AMIDA-2017, 27-29 November 2017, University of Montpellier-France.

Loke, M. H. \& Barker, R. D. (1996b). Practical techniques for 3D resistivity surveys and data inversion techniques. Geophysical Prospecting 44, 499-524.

Loke, M. H. \& Barker, R. D. (1996a). Rapid least-squares inversion of apparent resistivity pseudosections using a quasi-Newton method. Geophysical Prospecting, 44, 131-152.

Sasaki, Y. (1992). Resolution of resistivity tomography inferred from numerical simulation. Geophysical Prospecting 40, 453-463.

Şahan, Ç., Şiranün, S., Öztürk, R., Aksakal, O. A., Kaynak, E., Avcıŏlu, H., \& Kurtuluş, C. (2016). Jeofizik Yöntemlerle Yanal Süreksizliklerin İncelenmesi. Uygulamalı Yerbilimleri Dergisi, 11(1), 59-65.

Toker, C. E. (2014). Simav Havzasının Jeofizik Verilerle Analizi ve Modellenmesi, Batı Anadolu. Maden Tetkik ve Arama Dergisi, 148(148), 119-135.

Uyanık, O., \& Çatlığlu, B. (2014). Elektrik Özdirenç ve Sismik Kırılma Yöntemlerinden Heyelan Geometrisinin Belirlenmesi. Journal of Natural \& Applied Sciences, 18(3).

Van Overmeeren, R. A. \& Ritsema, I. L. (1988). Continuous vertical electrical sounding, First Break, 6(10), 313-324. 